\title{
Development of a Shower Carrier based on the Needs in Long-term Care Institutions
}

\author{
Deok Yeon Cho ${ }^{1}$, Cheol Woong Ko ${ }^{1}$, Keyoung Jin Chun ${ }^{1}$, Kon Woo No ${ }^{2}$ \\ ${ }^{1}$ Gerontechology R\&D Group, Korea Institute of Industrial Technology (KITECH), Cheonan, 331-825 \\ ${ }^{2}$ Rehabilitation Team, Seoul National Seobu Senior Care Center, Seoul, 121-250
}

\begin{abstract}
Objective: This study developed a new shower carrier prototype to reduce caregivers' muscle burden and to increase use convenience by reflecting the needs of domestic long-term care institutions. Background: In the long-term care institutions, one of the ADL(Activities of Daily Life) factors is bathing/showering. Recently, bath/shower-assisting equipment is actively being introduced in care institutions to reduce the caregivers' care cost, but most of the domestic equipment was designed to imitate foreign products and rarely reflected the needs of care institutions. Method: Based on Korean elderly people's body information, the bed size(length: $1,900 \mathrm{~mm}$, width: $650 \mathrm{~mm}$ ) was set-up, and a variable headrest with a newly designed headform was developed to provide the comfort for the elderly and convenience for caregivers. To reduce caregivers' muscle burden on transferring and showering activities, a 3-step column lifting module equipped with dual actuators(lowest/highest levels from the ground: $600 / 1,100 \mathrm{~mm}$, Stroke: $500 \mathrm{~mm}$ ) was developed, and the wheelbase parameter(length: 1,250mm, width: 580mm) was defined securing the turn-over safety of the shower carrier. The drivability tests were performed for the prototype and foreign product, and the male and female subject's muscle activities were measured through the tests. Results: The structural stability of the shower carrier prototype was secured by finite element analysis, and the muscle activities of the subjects through the drivability tests largely decreased in the prototype, compared to the foreign product. Conclusion: In this study, a new shower carrier prototype was developed to possibly reduce caregivers' muscle burden and to increase use convenience based on the needs of long-term care institutions. It was expected that the drivability performance of the prototype could be relatively superior to that of the foreign product. Application: The results obtained from the study can be applied for the optimal development of a shower carrier including other equipment to effectively care for the elderly.
\end{abstract}

Keywords: Aging, Long-term care institution, Shower carrier, Caregiver, Drivability test

\section{Introduction}

최근 경제성장 및 의료기술의 발전에 따라 세계적으로 급 격한 고령화가 진행되고 있으며, 심각한 사회 문제로 부각 되고 있다. 한국의 경우 이미 2000년에 고령화사회(65세 이상, $7 \%$ )로 진입한 이래, 세계에서 가장 빠른 속도로 고령
사회(65세 이상, $14 \%$ )에 진입 중이며, 2050년에는 초고령 사회(65세 이상, $40 \%$ )로의 진입이 전망된다(Ministry of Health and Welfare, 2006). 고령자의 경우, 약 $4 \%$ 는 간병 수발 혹은 장기요양기관 수용이 요구되는 장애 1,2 등급의 상태이며, 나머지에서 $8.3 \%$ 는 허약(Frail) 상태로 독거 혹 은 재가의 생활 형태이다(The Ministry of Health and Welfare, 2008).

Corresponding Author: Cheol Woong Ko. Gerontechology R\&D Group, Korea Institute of Industrial Technology (KITECH), Cheonan, 331-825. Mobile: 010-2968-1107, E-mail: cheko@kitech.re.kr Copyright@2012 by Ergonomics Society of Korea(pISSN:1229-1684 eISSN:2093-8462). All right reserved.

(c)This is an open-access article distributed under the terms of the Creative Commons Attribution Non-Commercial License(http://creativecommons.org/licenses/by-nc/3.0/), which permits unrestricted non-commercial use, distribution, and reproduction in any medium, provided the original work is properly cited. 
일반적으로 장기요양기관에서의 일상생활 수행능력(ADL: Activity of Daily Life)의 주요 4대 요소는 식사, 배변, 이송/ 이동 및 목욕/샤워이다(The Korean Gerontological Society, 2002). 특히, 삶의 질(QoL: Quality of Life) 관점에서 볼 때, 목욕/샤워행위는 노폐물을 제거하여 청결을 유지시키고, 질병 치료나 억제, 그리고 이차적인 질병 예방의 효과가 있 고, 무엇보다도, 신체기능의 질병이나 장애와 관계 없이 주 기적 또는 반복적으로 이루어져야 하는 필수 활동이다. 하 지만, 목욕/샤워행위는 거동이 불편한 고령자에게는 수발자 $1 \sim 2$ 인의 도움 없이는 독립적으로 이루어질 수 없기 때문에, 수발자에게 많은 보호비용(Care Cost)이 요구되는 행위이 기도 하다. 또한, 목욕/샤워행위는 장기요양보험에서 정액 수가를 받는 행위에 포함되었기 때문에(Long-term Care Insurance, 2008), 고령자에 대한 목욕/샤워행위의 효율성 과 질적인 부분이 중요하게 인식되고 있다. 따라서 수발자의 근력 부담을 경감시키고, 사용자의 편의성 향상이 기대되는 목욕/샤워 보조장비의 개발이 절실하게 요구된다.

최근, 장기요양기관에서는 수발자의 보호비용 경감을 위하 여 다양한 목욕/샤워 보조장비가 적극적으로 도입되고 있으 며, 샤워캐리어는 대표적인 보조장비 중의 하나이다. 하지만 국내에서 판매되고 있는 샤워캐리어는 주로 외국제품을 모 방한 제품이 대부분이며, 요양기관에서의 요구사항이 반영되 어 개발된 제품은 거의 없다. 따라서 본 연구에서는, 국내 장 기요양기관에서의 요구사항을 반영하여, 사용자의 편의성 향 상과 수발자의 근력 부담 경감이 가능한 샤워캐리어 시제품 을 개발하였다.

\section{Field Survey in Care Institutions}

샤워캐리어는 장기요양기관에서 주로 사용되는 대표적인 목욕/샤워 보조장비다. 따라서 장비의 편의성과 활용도를 높이기 위해서는 요양기관의 환경 조건, 수발자의 행동특성 등이 충분히 반영된 제품개발이 요구된다. 본 연구에서는 국내 3 개소의 중대형 요양기관 환경과 고령자의 목욕/샤워 행위에 수반되는 수발자의 행동패턴을 조사하였고, 장비에 대한 수발자의 요구사항에 대하여 설문조사를 실시하였다 (Table 1).

요양기관의 환경을 조사한 결과(Figure 1), 출입문 폭은 900 1,100mm, 복도 폭은 3,000 3,300 mm로 확인되었 고, 최근 수발자의 부담 경감을 위하여 적극적으로 도입되고 있는 저상형 침대 높이는 550 600mm로 확인되었다. 한 편, 비디오 촬영을 통하여 수발자의 행동패턴을 분석한 결 과, 침대에서 샤워캐리어로의 고령자 이송행위, 샤워실로의

이동행위, 그리고 수발자의 샤워 수발행위로 구분되었다. 이 송행위는 침대와 같은 높이에서 이루어지고, 이동행위에서의 Gripping 조건은 수발자의 팔꿈치 높이로 확인되었으며, 샤 워 수발행위는 주로 수발자의 허리 높이 $(1,100 \mathrm{~mm})$ 에서 수 행되는 것으로 나타났다. 또한, 설문조사 결과로부터, Bed 부의 최대화, 제품의 경량화, 장비의 안전성 확보에 대한 요 구사항이 확인되었다.

Table 1. Summary of field survey on care institutions

\begin{tabular}{|c|c|}
\hline \multicolumn{2}{|r|}{ Major Needs } \\
\hline $\begin{array}{l}\text { Environmental } \\
\text { conditions }\end{array}$ & $\begin{array}{l}\text { Door width: } 900 \sim 1,100 \mathrm{~mm} \\
\text { Corridor width: } 3,000 \sim 3,300 \mathrm{~mm} \\
\text { Low platform bed height: } 550 \sim 600 \mathrm{~mm}\end{array}$ \\
\hline $\begin{array}{l}\text { Behavioral patterns } \\
\text { of caregivers }\end{array}$ & $\begin{array}{l}\text { Transferring at bed height } \\
\text { Gripping at elbow height of caregiver } \\
\text { Showering at waist height of caregiver }\end{array}$ \\
\hline $\begin{array}{l}\text { Requirements on } \\
\text { equipment }\end{array}$ & $\begin{array}{l}\text { Maximizing bed size } \\
\text { Lightening weight } \\
\text { Securing safety }\end{array}$ \\
\hline
\end{tabular}

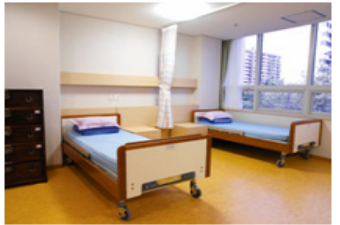

General Platform: 650 750mm

Low Platform: 550 600mm
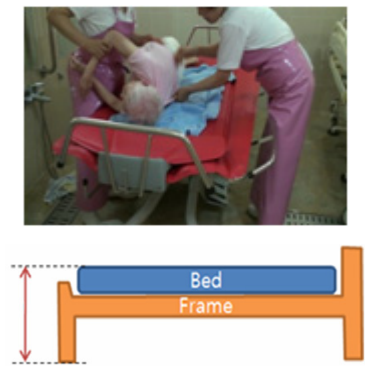

Figure 1. Examples of field survey of care institutions

\section{Bed Assembly of Shower Carrier}

\subsection{Bed frame size}

수발자의 근력 부담 경감을 통하여 효율적인 샤워수발이 가능하도록 샤워캐리어 Bed 부의 Size 선정이 필요하다. 따 라서, 샤워수발 시, 고령자의 자세변환이 용이하도록 Bed 부 크기의 최대화가 요망되나, 요양기관의 환경 조건도 고려해 야 된다. 본 연구에서는, 한국인 60대 남녀 고령자의 최대 신장/최대 위팔사이너비(Size Korea, 2004)와 요양기관 환 경 (출입문 폭: 900 1,100mm)을 반영하여 (Table 2), Bed 부 길이는 $1,900 \mathrm{~mm}$, 폭은 $650 \mathrm{~mm}$ 로 설정하였다. 
Table 2. Body Information of Korean elderly(Size Korea, 2004)

\begin{tabular}{c|c|c}
\hline Body & Male & Female \\
\hline Stature $(\mathrm{mm})$ & 1,816 & 1,676 \\
\hline Bideltoid breadth $(\mathrm{mm})$ & 507 & 495 \\
\hline
\end{tabular}

\subsection{Variable headrest with tilting mechanism}

샤워 수발행위는 일반적으로 세신과 세발로 구분된다. 세 신 시에는 고령자의 눈 혹은 코로 물이 유입되어 고령자에게 불편함을 준다. 한편, 머리가 고정된 상태에서의 효율적인 세발을 위해서는 고령자 머리의 상하 움직임이 빈번하게 요 구되기 때문에 수발자에게 많은 부담을 가중시키는 것이 확 인되었다. 따라서, 샤워캐리어의 Headrest에는, 세신 시에는 상향으로 Tilting되어 고령자의 불편함이 최소화됨에 따라 사용 편의성을 향상시키고, 세발 시에는 하향으로 Tilting되 어 수발자의 부담 경감이 가능한 가변형 구조가 요망된다.

본 연구에서는 세신 및 세발 시의 요구사항을 고려하여 새로운 가변형 Headrest Mechanism을 고안하였다. 상향 Tilting (최대 $15^{\circ}$ 전후) 시에는, One-way Bearing에 의 하여 Locking 기능을 확보하였고, Stopper 기능을 추가하 였다. 한편, 하향 Tilting(최대 $10^{\circ}$ 전후) 시에는, 수발자의 Gripping에 의해 작동되는 구조로 설정하였고, 급격한 움직 임 방지를 위하여 Damper를 적용하였다. 이러한 Headrest Mechanism의 구조 안전성을 검토하기 위하여 60대 남성 머리의 최대 중량 $(8 \mathrm{~kg})$ 을 고려한 유한요소해석(ANSYS v.12.1, USA)을 수행하였다. 해석 결과, 최대 변형 $(0.17 \mathrm{~mm})$ 및 최대 응력 $(96.12 \mathrm{MPa})$ 이 도출되어 가변형 Headrest Mechanism의 구조 안전성이 확보되었으며(Figure 2), 이를 토대로 가변형 Headrest 시제품을 개발하였다(Figure 3).

\subsection{Headform with head morphological information}

Headform은 이동 및 샤워수발 시 고령자의 머리를 견고 하게 지지하여 안락감 등의 사용자의 편의성 제공은 물론, 불필요한 수발행위를 감소시켜 주는 중요한 설계요소 중의 하나이다. 따라서, 머리 부위에서의 국부적 압박감을 경감시 키고 머리부위 지지에 적합한 Headform 형상이 요구된다. 본 연구에서는 60 대 남성의 머리/목 부위의 MRI 정보를 이 용하여 Headform 형상을 도출하였고, 3차원 머리형상이 반 영된 Headform (재질: Polyurethane, 밀도: $25 \mathrm{~kg} / \mathrm{cm}^{3}$ ) 시 제품을 개발하였다(Figure 4). Headform 시제품에 대해서 는, 체압매트 $(2.0 \mathrm{~m} * 1.0 \mathrm{~m}$, Novel 사, Germany)를 사용하 여 남성 피검자 5 인에 대한 머리/목 부위의 체압시험을 수 행하였다. 시험 결과, 형상 미반영 조건 대비 약 $19.1 \%$ 의
체압분산 효과(형상 미반영 최대 압력: $6.8 \pm 0.8 \mathrm{kPa}$, 형상 반영 최대 압력: $5.5 \pm 1.0 \mathrm{kPa}$ ) 가 확인되었다(Figure 5).

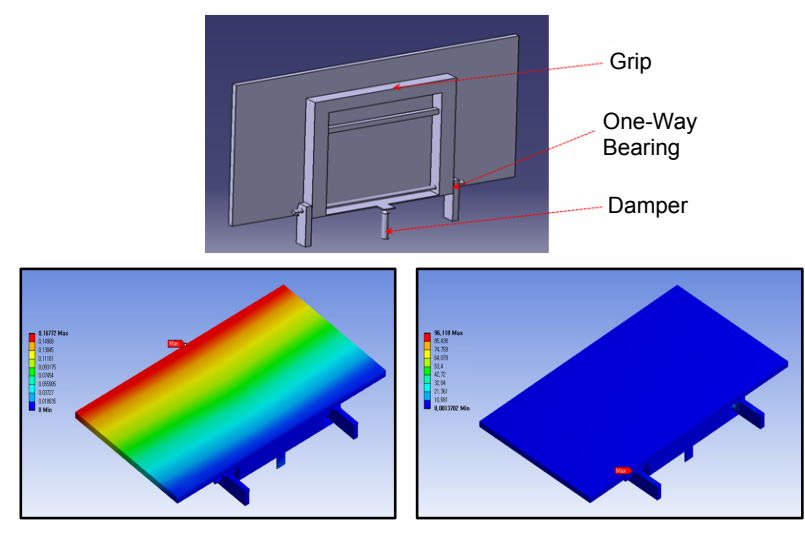

Figure 2. Concept design and FE Analysis of variable headrest mechanism(Left: Deformation, Right: Stress)
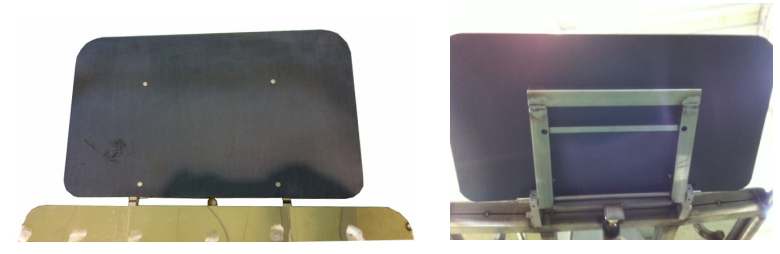

Figure 3. Prototype of variable headrest with tilting mechanism
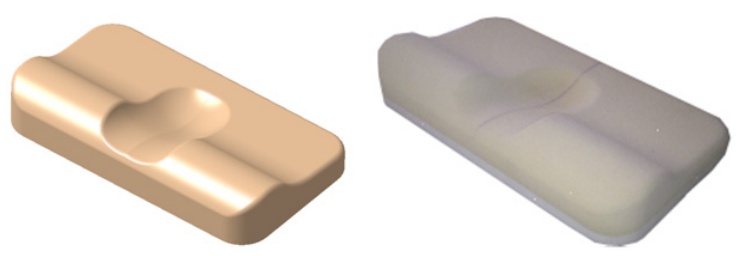

Figure 4. Headform with human head morphological information
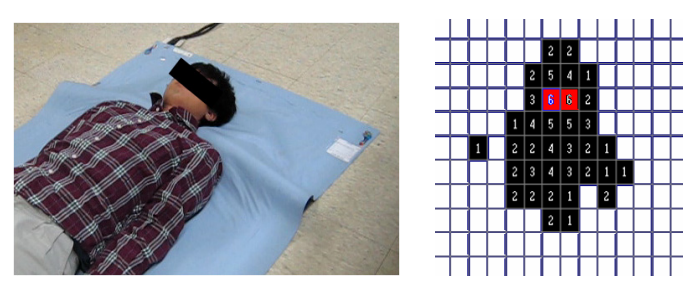

Figure 5. Measurement of body pressure using headform 


\section{Lifting Module of Shower Carrier}

\subsection{Three-step column lifting module system}

샤워캐리어의 승하강 구동부는 일반적으로 X-Type과 Column Type으로 구분 가능하다. X-Type의 샤워캐리어 는 Link 길이 조절을 통하여 최저/최고 지상고 조절이 용이 하나, Bed 부 하단의 공간 효율성이 떨어지며 구조가 복잡하 여, 심미성이 저하되는 단점이 있다. 한편, Column Type의 샤워캐리어는 Linear Actuator에 의하여 Bed 부가 구동되 며, 승하강 시의 Bending Moment는 Column에 의하여 지 지된다. 이러한 Column Type은 Bed 부 하단의 공간 효율 성과 심미성이 우수하나, 기존 제품에서의 최대 Stroke는 약 $300 \mathrm{~mm}$ 이하가 대부분이다.

본 연구에서는, 요양기관에서 고령자 이송 및 샤워수발 시 수발자의 근력 부담 경감이 가능하도록 Column의 최저/최 고 지상고를 600/1,100mm(Stroke: 500mm)로 설정하였 다. 2단 Column 구조에서는 Stroke $500 \mathrm{~mm}$ 는 만족하나 설정된 지상고 $(600 ~ 1,100 \mathrm{~mm})$ 구현이 불가하다. 따라서, Column 내부에 상하 반대로 장착되는 Dual Type Linear Actuator (Stroke: 250mm*2, LA28, LINAK, Denmark) 를 적용하여, 3 단 Column 구조의 Lifting Module System을 신규로 고안하였다(Figure 6). 이러한 구조를 통하여 설정된 지상고 $(600 ~ 1,100 \mathrm{~mm})$ 와 Stroke $500 \mathrm{~mm}$ 의 동시 구현이 가능한 샤워캐리어용 저소음 3단 Column Lifting Module 시제품을 개발하였다(Figure 7, Table 3).

\subsection{Mechanical tests of lifting module system}

Column Type의 Lifting Module은 중앙에서 Bed 부를 지지하는 구조이지만, Bed 부 양단에 작용되는 하중으로 인 한 Bending Moment는 승하강 성능에 영향을 줄 수 있다. 본 연구에서는 Lifting Module 시제품의 성능 확인을 위하 여 정적 편하중 Bending 시험과 승하강 피로시험을 수행하 였다.

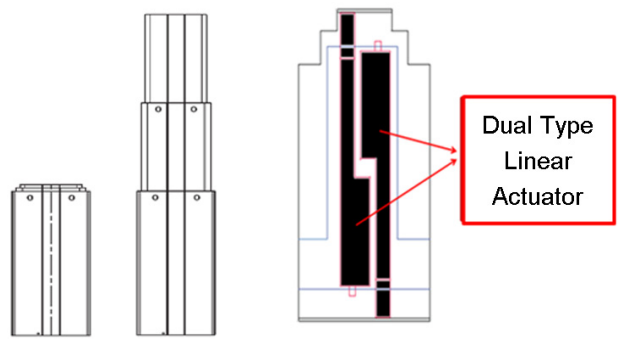

Figure 6. New design concept of 3-step column lifting module system with dual type linear actuators
정적 편하중 Bending 시험 조건으로서 샤워캐리어의 최 대 하중 조건 $(2,000 \mathrm{~N})$ 을 고려하여 $200 \mathrm{~kg}$ 의 추를 Column 중심에서 $1 \mathrm{~m}$ 떨어진 지점에 적용하였고, Lifting Module의 승하강 구동을 확인하였다. 시험을 통하여, Column의 균열, 변형, 행정 간 소음을 확인하고, Actuator의 과전류, 승하강 속도를 확인하여 Lifting Module의 기본 성능을 확보하였다 (Figure 8).

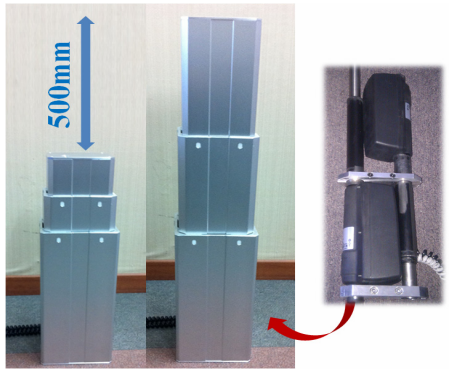

Figure 7. Prototype of 3-step column lifting module system

Table 3. Specification of 3-step column lifting module system

\begin{tabular}{c|c}
\hline \multicolumn{2}{c}{ Major specification } \\
\hline Column base size & $163 * 163 \mathrm{~mm}$ \\
\hline Max. stroke & $500 \mathrm{~mm}$ \\
\hline Max. allowable load & $3,500 \mathrm{~N}$ \\
\hline Lifting speed & $10 \sim 12 \mathrm{~mm} / \mathrm{s}$ \\
\hline Lifting noise & $47 \mathrm{~dB}$ \\
\hline
\end{tabular}
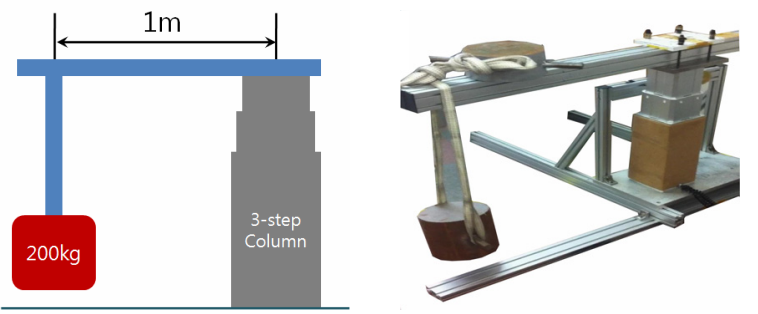

Figure 8. Static bending test of 3-step column lifting module

한편, 승하강 피로시험이 가능한 시험장비를 제작하여 Lifting Module의 내구성 시험을 실시하였다. 내구성 시험을 위하여 자동 승하강 구동 Controller를 제작하였다. 요양시 설에서의 실제 사용 조건을 고려하여, Lifting Module 상부 에 $150 \mathrm{~kg}$ 의 하중(인체 Dummy 40kg + Steel Plate 60kg + 시험장비 승하강 부 중량 $50 \mathrm{~kg})$ 을 적용하였다. 또한, 승강시간 $\left(\mathrm{t}_{1}\right)$, 하강시간 $\left(\mathrm{t}_{2}\right)$, 휴지시간 $\left(\mathrm{t}_{3}\right)$ 을 $1 \mathrm{Cycle}(\mathrm{t}=$ $\mathrm{t}_{1}+\mathrm{t}_{2}+\mathrm{t}_{3}$ )로 설정하여 총 $10,000 \mathrm{Cycle}$ (Actuator의 내구 
성능 조건)의 피로시험을 완료하였다(Figure 9). 시험 결과, 승하강 구동에 따른 Column의 균열, 변형, 이상 마모가 없 었으며, Dual Actuator와의 설계 정합성도 확보되었다.
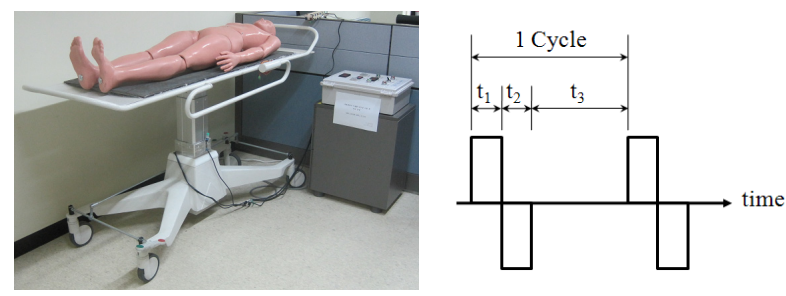

Figure 9. Fatigue test set-up and lifting cycle pattern

\section{Base Frame of Shower Carrier}

고령자의 샤워 수발행위에 있어서 샤워캐리어와 같은 보 조장비를 이용하는 경우, 탑승한 고령자에 대한 안전성이 무 엇보다도 중요하다. 특히, 실내이동 시의 평지 및 경사면에 서의 전도 안전성은 반드시 확보되어야 한다. 이에 따라, 본 연구에서는 샤워캐리어의 정역학적 전도해석을 통하여 전도 안전성을 검토하였다.

전도해석에 필요한 인체의 체중 $\left(\mathrm{W}_{\text {human }}\right)$ 과 무게중심 (C.M) 위치 $(\mathrm{G})$ 에 대해서는, 한국인 60대 남녀의 체중과 신체분절 질량비 (Park et al., 1996)를 이용하여 산출하였다(Figure 10, Table 4, Eq. 1). 또한, Bed 부 길이, 폭, 중량 등의 설 계변수와 외부 하중 $(\mathrm{F})$ 을 설정하여 평지와 경사면에서의 Wheelbase 설계변수를 도출하였다. 특히, 경사면에 대해 서는 한국고령친화용품산업협회 단체표준(iSTANDARD, 2010)에 규정된 $10^{\circ}$ 의 경사면 조건을 적용하였다(Figure 11 , Eq. 2 to 4). 전도해석 결과, 전도 안전성이 확보 가능한 최소 Wheelbase가 얻어졌고, 안전계수를 고려하여 샤워캐

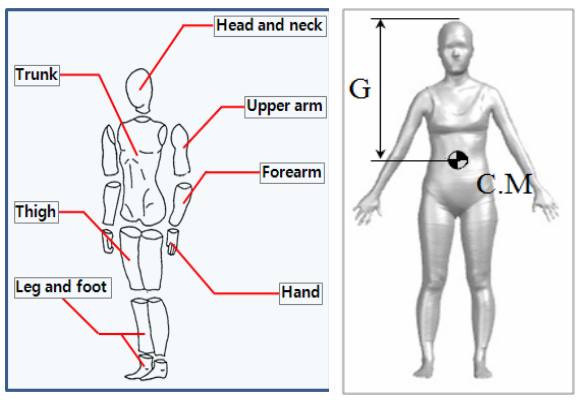

Figure 10. Calculation of $\mathrm{G}$ from head to C.M
리어의 Wheelbase (길이 방향: $1,250 \mathrm{~mm}$, 폭 방향: 580 $\mathrm{mm}$ )를 선정하였다. 이를 기초로 심미성이 고려된 일체형의 Base Frame을 설계하였다(Figure 12).

Table 4. Human segmental data of Koreans in their 60s

\begin{tabular}{c|r|r|r|r|r}
\hline \multirow{2}{*}{ Body Part } & \multirow{2}{*}{$\%$} & \multicolumn{2}{|c|}{ Weight(kg) } & \multicolumn{2}{c}{ Stature(mm) } \\
\cline { 3 - 6 } & & Male & Female & Male & Female \\
\hline Head \& neck & 8.98 & 8.04 & 7.97 & 269 & 249 \\
\hline Trunk & 48.86 & 43.73 & 43.34 & 697 & 661 \\
\hline Thigh & 10.47 & 9.375 & 9.29 & 359 & 310 \\
\hline Leg with foot & 5.74 & 5.14 & 5.09 & 491 & 456 \\
\hline Upper arm & 2.73 & 2.44 & 2.42 & 374 & 341 \\
\hline Forearm & 1.52 & 1.36 & 1.35 & 307 & 274 \\
\hline Hand & 0.62 & 0.55 & 0.55 & 207 & 202 \\
\hline Total & 100 & 89.5 & 88.7 & 1,816 & 1,676 \\
\hline
\end{tabular}
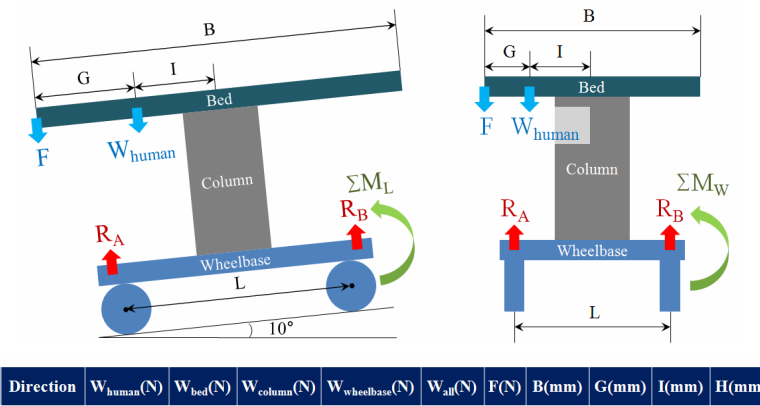

\begin{tabular}{|c|c|c|c|c|c|c|c|c|c|c|}
\hline Length & 887 & 250 & 250 & 200 & 1587 & 816 & 1,900 & 746 & 204 & 1,100 \\
\hline
\end{tabular}

\begin{tabular}{|c|c|c|c|c|c|c|c|c|c|c|}
\hline Width & 887 & 250 & 250 & 200 & 1587 & 816 & 650 & 210 & 115 & 1,100 \\
\hline
\end{tabular}

Figure 11. Schematic diagram for turn-over analysis

$\mathrm{G}=\frac{\sum_{\mathrm{k}=1}^{\mathrm{n}} \mathrm{m}_{\mathrm{k}} \mathrm{r}_{\mathrm{k}}}{\sum_{\mathrm{k}=1}^{\mathrm{n}} \mathrm{m}_{\mathrm{k}}}$

$\mathrm{W}_{\mathrm{all}} \mathrm{x} \cos \theta+\mathrm{F}=\mathrm{R}_{\mathrm{A}}+\mathrm{R}_{\mathrm{B}}$

$\sum \mathrm{M}_{\mathrm{L}}=\left(\mathrm{W}_{\text {all }} \times \cos \theta+\mathrm{F}-\mathrm{R}_{\mathrm{B}}\right) \times \mathrm{L}-\left(\mathrm{W}_{\text {human }} \times \cos \theta\right) \times(\mathrm{I}+\mathrm{L} / 2)$

$-\mathrm{W}_{\text {bed }} \times \cos \theta \times(\mathrm{L} / 2)-\mathrm{W}_{\text {column }} \times \cos \theta \times(\mathrm{L} / 2)$

$-\mathrm{W}_{\text {wheelbase }} \times \cos \theta \times(\mathrm{L} / 2)-\mathrm{W}_{\text {human }} \times \sin \theta \times \mathrm{H}$

$-\mathrm{W}_{\text {bed }} \times \sin \theta \times \mathrm{H}-\mathrm{W}_{\text {column }} \times \sin \theta \times(\mathrm{H} / 2)$

$-\mathrm{F} \times(\mathrm{B} / 2+\mathrm{L} / 2)$

$\sum \mathrm{M}_{\mathrm{W}}=\left(\mathrm{W}_{\mathrm{all}}+\mathrm{F}-\mathrm{R}_{\mathrm{B}}\right) \times \mathrm{L}-\mathrm{W}_{\text {human }} \times(\mathrm{I}+\mathrm{L} / 2)$

$-\mathrm{W}_{\text {bed }} \times(\mathrm{L} / 2)-\mathrm{W}_{\text {column }} \times(\mathrm{L} / 2)$

$-\mathrm{W}_{\text {wheelbase }} \times(\mathrm{L} / 2)-\mathrm{F} \times(\mathrm{B} / 2+\mathrm{L} / 2)$ 

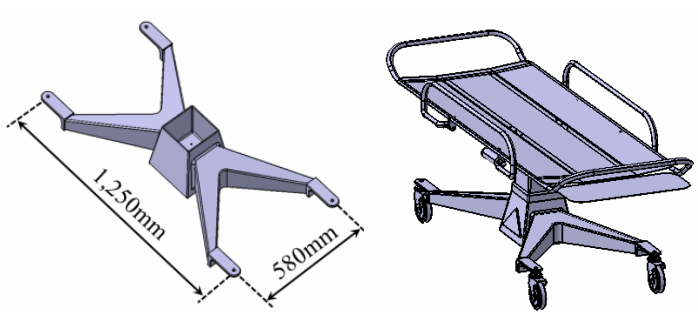

Figure 12. 3D model of shower carrier with base frame

선정된 Wheelbase가 반영된 Base Frame을 적용하여 샤 워캐리어의 3 차원 모델을 구축하였고, 유한요소해석을 통 하여 구조 안전성을 검증하였다. 하중 조건으로 $\mathrm{Bed}$ 부에 $2,500 \mathrm{~N}$ 의 분포 하중을 적용하였고, 경계 조건으로서 샤 워캐리어 Wheel을 완전 고정하였다. Bed Frame의 재질 에는 Stainless Steel을, Lifting Module Column과 Base Frame에는 Al Alloy를 적용하였다. 해석 Solver는 ANSYS Workbench v.12.1 (ANSYS Inc., USA)을 이용하였다. 해 석 결과, Base Frame의 최대 Von Mises 응력은 $41.6 \mathrm{MPa}$ 로 얻어져, 샤워캐리어의 구조 안전성 (Al Alloy 인장강도: $124 \mathrm{MPa}$ )이 확보되었다(Figure 13).
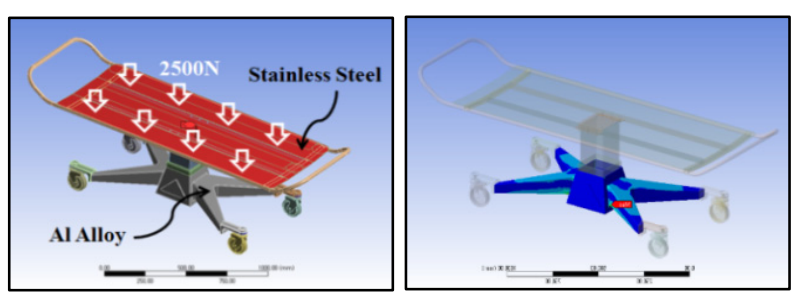

Figure 13. Loading condition and result of FE analysis

\section{Drivability Tests}

\subsection{Preparation of drivability tests}

본 연구에서는 요양기관에서의 요구사항을 반영하여, 사용 자의 편의성 향상과 수발자의 근력 부담 경감이 기대되는 샤 워캐리어 시제품을 개발하였다. 시제품의 주행 성능 검증을 위하여, 경쟁제품 (Forelli, Horcher Lifting Systems Inc, Germany)을 선정하였고 주행성 시험을 수행하였다(Figure 14, Table 5). 주행성 시험 시, EMG(Electromyography) 센서를 이용하여 피검자의 근활성도를 측정하였고, 이를 기 초로 수발자의 근력 부담 정도를 비교/분석하였다. $\mathrm{EMG}$ 는 운동 중 근육의 전기적 활동을 측정하는 것으로 스포츠 의학,
인간공학, 전문 임상실험 등의 연구분야에 효과적으로 사용 된다(Electromyography, 2011).
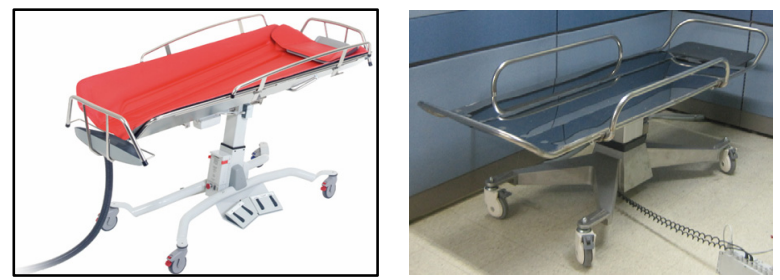

Figure 14. Shower carriers used for drivability tests

Table 5. Specification of shower carriers

\begin{tabular}{c|c|c}
\hline Model & Forelli & Prototype \\
\hline Maker & Horcher & KITECH \\
\hline Country & Germany & Korea \\
\hline Bed size $(\mathrm{mm})$ & $2,090 * 740$ & $1,900 * 650$ \\
\hline Wheelbase size $(\mathrm{mm})$ & $1,350 * 650$ & $1,250 * 580$ \\
\hline Wheel diameter $(\mathrm{mm})$ & $\varnothing 120$ & $\varnothing 125$ \\
\hline Weight $(\mathrm{kg})$ & 85 & 65 \\
\hline
\end{tabular}

일반적으로 요양기관에서의 수발자는 주로 20대 남성과 4 50대 여성으로 구성되어 있다. 본 연구에서는 주행성 시 험을 위한 피검자로서, 근골격계 질환이 없는 건강한 20 대 남성 5인(연령: $27.5 \pm 0.5$ 세, 체중: $76 \pm 6 \mathrm{~kg}$, 신장: $173.5 \pm$ $5.5 \mathrm{~cm}$, 어깨너비: $44 \pm 2 \mathrm{~cm}$, 팔꿈치 높이: $108.5 \pm 3.5 \mathrm{~cm})$ 과 40 대 여성 5 인 (연령: $44.5 \pm 2.5$ 세, 체중: $52.5 \pm 3.5 \mathrm{~kg}$, 신장: $160 \pm 2 \mathrm{~cm}$, 어깨너비: $38.5 \pm 22.5 \mathrm{~cm}$, 팔꿈치 높이: $104.5 \pm 4.5 \mathrm{~cm})$ 을 선정하였다.

피검자의 근활성도 측정하기 위하여, 남성의 경우에는 주행 시 활성화가 예상되는 상반신 8개소의 근육(대흉근: PMM/ Pectoralis Major Muscle, 삼각근: DM/Deltoid Muscle, 위팔두갈래근: BBM/Biceps Brachii Muscle, 자쪽손목굽 힘근: FCUM/Flexor Carpi Ulnaris Muscle, 승모근: TM/ Trapezius Muscle, 위팔세갈래근: TBM/Triceps Brachii Muscle, 긴노쪽손목폄근: ECRLM/Extensor Carpi Radialis Longus Muscle, 척주기립근: ESM/Erector Spinae Muscle) 을 선정하였다(Figure 15). 여성의 경우, 대흥근 부위에는 피하지방의 과다 분포로 측정된 근활성도의 신뢰성에 문제 점이 예상되어, 본 연구에서는 대흥근을 제외한 7 개소의 근 육을 선정하였다(Figure 16). 근활성도 측정을 위한 $\mathrm{EMG}$ 센서는 Telemyo 2400T-G2(Noraxon Inc., USA)를 이 용하였다. 


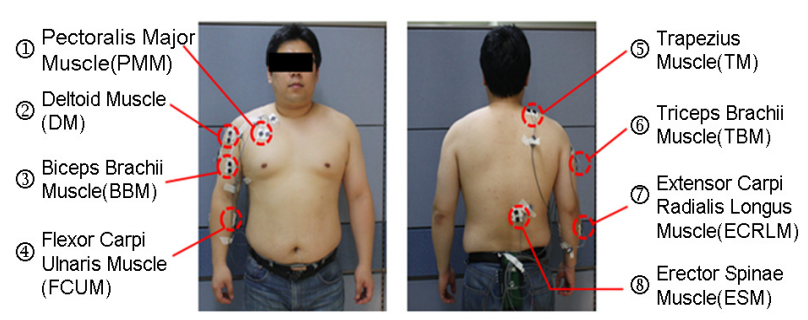

Figure 15. EMG Sensor attached on selected 8 muscles

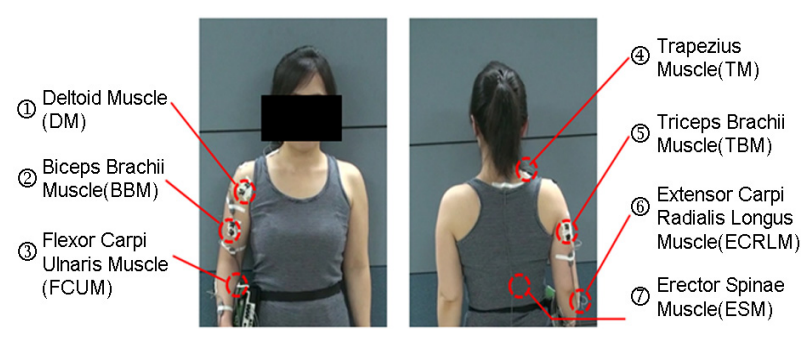

Figure 16. EMG Sensor attached on selected 7 muscles

\subsection{Conditions of drivability tests}

주행 조건은 요양기관에서 실제적으로 이루어지고 있는 수발자의 행동패턴을 반영하여 평지직진, 경사직진, 회전의 3 Type으로 선정하였다(Figure 17). 피검자 근육의 충분 한 활성화를 위하여, 평지직진 및 경사직진의 경우에는 출발 지점으로부터 5 보 진행 중에 근활성도를 측정하였고, 회전의 경우에는 샤워캐리어의 전방 1 개소의 Wheel을 축으로 하여 $90^{\circ}$ 회전 중에 근활성도를 측정하였다.

Gripping 조건은, 수발자의 실제 이동행위 시 행동패턴에 대한 비디오 촬영 영상을 분석하여, 피검자의 어깨 폭과 팔 꿈치 높이로 설정하였다(Figure 18). 또한, 고령자 탑승을 고려하여 Bed 부에 $60 \mathrm{~kg}$ 인체 Dummy를 탑재하였다. 시험 횟수는 3 Type의 주행 조건 별 남녀 피검자에 대하여 총 8회를 실시하였으며, 최대/최소를 제외한 6 회의 측정 결과 를 분석하였다(Figure 19)

\subsection{Data processing and analysis}

$\mathrm{EMG}$ 신호는 센서의 부착위치와 피검자의 신체적 컨디션 등에 따라 많은 영향을 받으므로, 객관적인 비교/분석을 위 하여 표준화(Normalization)가 필요하다. 표준화된 $\mathrm{EMG}$ 신호는 근활성도 분석에 적용 가능하며 통계적 처리에 유 용하다. 본 연구에서는 근육 별 측정 자세에 근거한 $\mathrm{SEED}$ Technology, 2010) 최대 자발적 수축(MVC: Maximum Voluntary Contraction)을 측정하여 EMG 신호의 표준화를
수행하였다(Figure 20). MVC 및 EMG Data에 대한 신호 처리(Signal Processing) 시에는, 근활성도 측정 결과에 영 향을 줄 수 있는 심전도(ECG: Electrocardiogram) 신호를 제거한 뒤, Filtering을 통하여 $10 \sim 350 \mathrm{~Hz}$ 이외의 Noise를 제거하였다. 이후, 진폭의 평균, 최대값, 면적의 값을 산출하

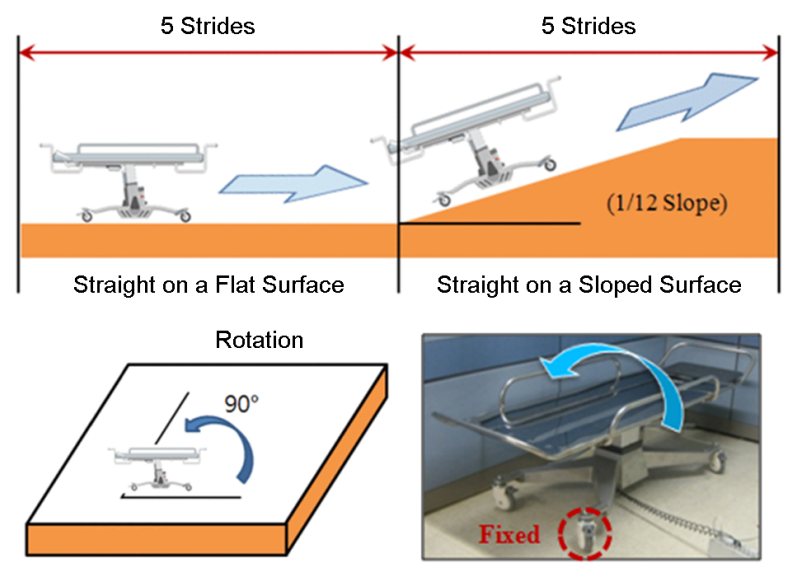

Figure 17. Three type test tracks for drivability tests
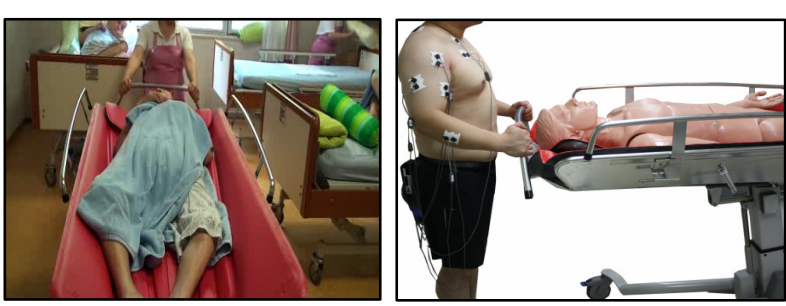

Figure 18. Gripping condition for drivability tests
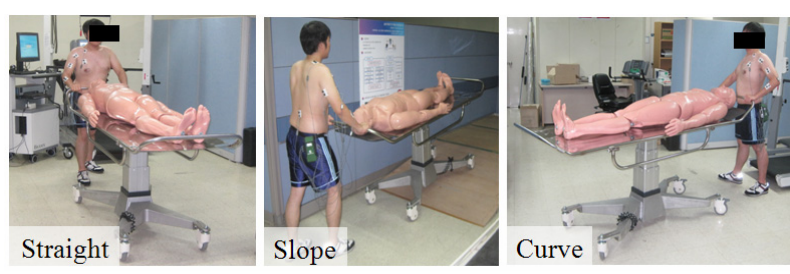

(a) Tests by male subjects
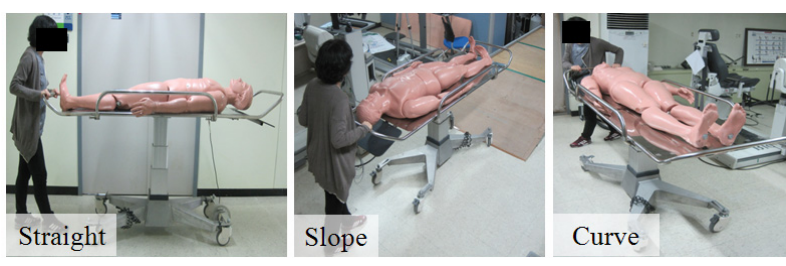

(b) Tests by female subjects

Figure 19. Drivability tests by subjects for each test track 
기 위하여 평활화 기법(RMS: Root Mean Square)을 사용 하였다.

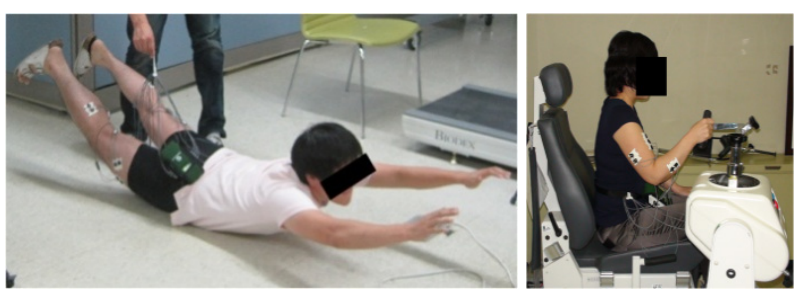

Figure 20. Examples of MVC measurement

\subsection{Test results}

본 연구에서는 경쟁제품(Forelli: A) 과 시제품(Prototype: B)에 대하여 주행성 시험을 통한 남녀 피검자의 최대 근활 성도를 분석하였다. 남성의 경우, 근활성도가 상대적으로 현 저하게 측정된 상위 3 개소의 근육은, 평지직진에서는 대흉근

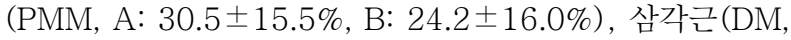
$\mathrm{A}: 32.9 \pm 8.7 \%, \mathrm{~B}: 20.4 \pm 17.1 \%)$, 척주기립근(ESM, A: $50.2 \pm 26.9 \%, \mathrm{~B}: 35.5 \pm 5.3 \%)$ 으로 확인되었고, 경사직진 에서도 대흉근(PMM, A: 46.2 $18.5 \%, \mathrm{~B}: 18.9 \pm 9.6 \%)$, 삼각근(DM, A: $58.1 \pm 18.2 \%, \mathrm{~B}: 29.5 \pm 17.1 \%$ ), 척주기립 근(ESM, A: $58.7 \pm 25.6 \%$, B: $43.5 \pm 9.6 \%$ )으로 확인되었 다. 하지만, 회전에서는 타 근육에 비하여 척주기립근 $(\mathrm{ESM}$, $\mathrm{A}: 28.9 \pm 9.8 \%, \mathrm{~B}: 21.7 \pm 7.9 \%)$ 에서만 상대적으로 높은
근활성도가 얻어졌다. 이러한 경향은 경쟁제품 $(\mathrm{A})$ 과 시제품 (B) 에서 모두 동일하게 확인되었다(Figure 21).

한편, 여성의 경우, 근활성도가 상대적으로 현저하게 측 정된 상위 3 개소의 근육은, 평지직진에서는 삼각근 $(\mathrm{DM}$, $\mathrm{A}: 25.4 \pm 14.0 \%, \mathrm{~B}: 24.2 \pm 10.8 \%)$, 위팔두갈래근(BBM, $\mathrm{A}: 32.1 \pm 17.7 \%, \mathrm{~B}: 31.3 \pm 13.3 \%$ ), 척주기립근(ESM, A: $24.7 \pm 7.2 \%$, B: $26.9 \pm 7.4 \%$ )으로 확인되었고, 경사직진에

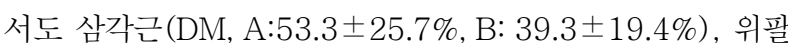
두갈래근(BBM, $\mathrm{A}: 86.5 \pm 10.4 \%, \mathrm{~B}: 60.8 \pm 19.7 \%)$, 척주 기립근(ESM, A: $39.2 \pm 10.4 \%, \mathrm{~B}: 37.1 \pm 7.2 \%)$ 으로 확인 되었다. 또한, 회전에서도 동일하게 삼각근 $(\mathrm{DM}, \mathrm{A}: 29.9 \pm$ $21.4 \%, \mathrm{~B}: 25.2 \pm 19.9 \%)$, 위팔두갈래근(BBM, A: $22.5 \pm$ $15.5 \%, \mathrm{~B}: 21.1 \pm 12.2 \%)$, 척주기립근(ESM, A: $23.2 \pm$ $6.6 \%, \mathrm{~B}: 21.4 \pm 5.2 \%$ )에서 상대적으로 현저한 근활성도가 얻어졌다. 이러한 경향은 경쟁제품 $(\mathrm{A})$ 과 시제품(B)에서 동 일하게 확인되었다(Figure 22).

\subsection{Discussions}

남성 피검자의 경우, 평지 및 경사직진에서는 대흉근 $(\mathrm{PMM})$, 삼각근(DM), 척주기립근(ESM)이 현저하게 활성 화된 반면, 회전에서는 척주기립근(ESM)이 주로 활성화되 었다. 이러한 근육을 대상으로 경쟁제품(A) 대비 시제품(B) 에 대한 근활성도 변화율을 비교한 결과, 평지직진에서는 -20.7 -38.0\% (PPM: -20.7\%, DM: -38.0\%, ESM: $-29.3 \%)$ 경사직진에서는 $-25.9 \sim-59.0 \%$ (PPM: $-59.0 \%$,
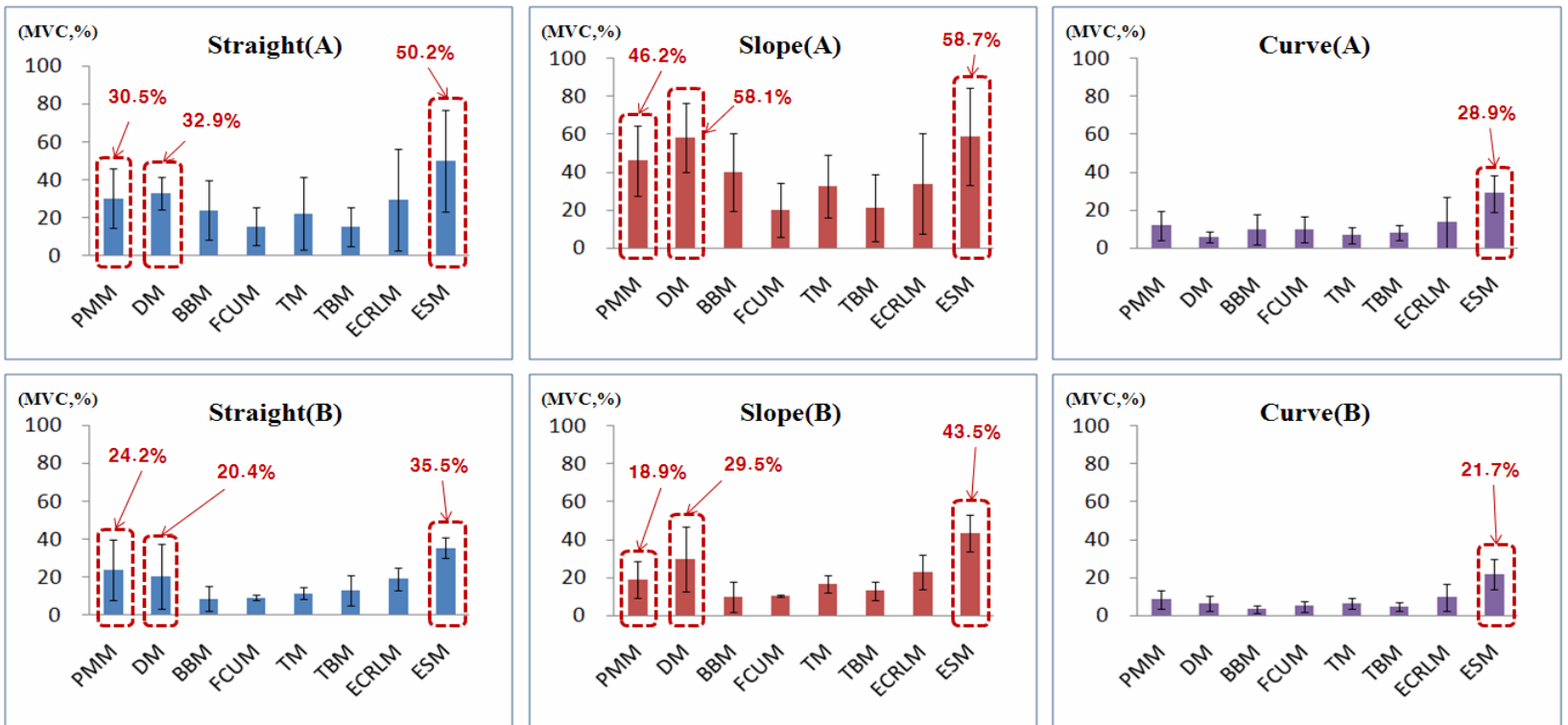

Figure 21. Comparison of muscle activities from drivability tests between shower carrier A and B in case of male subjects 

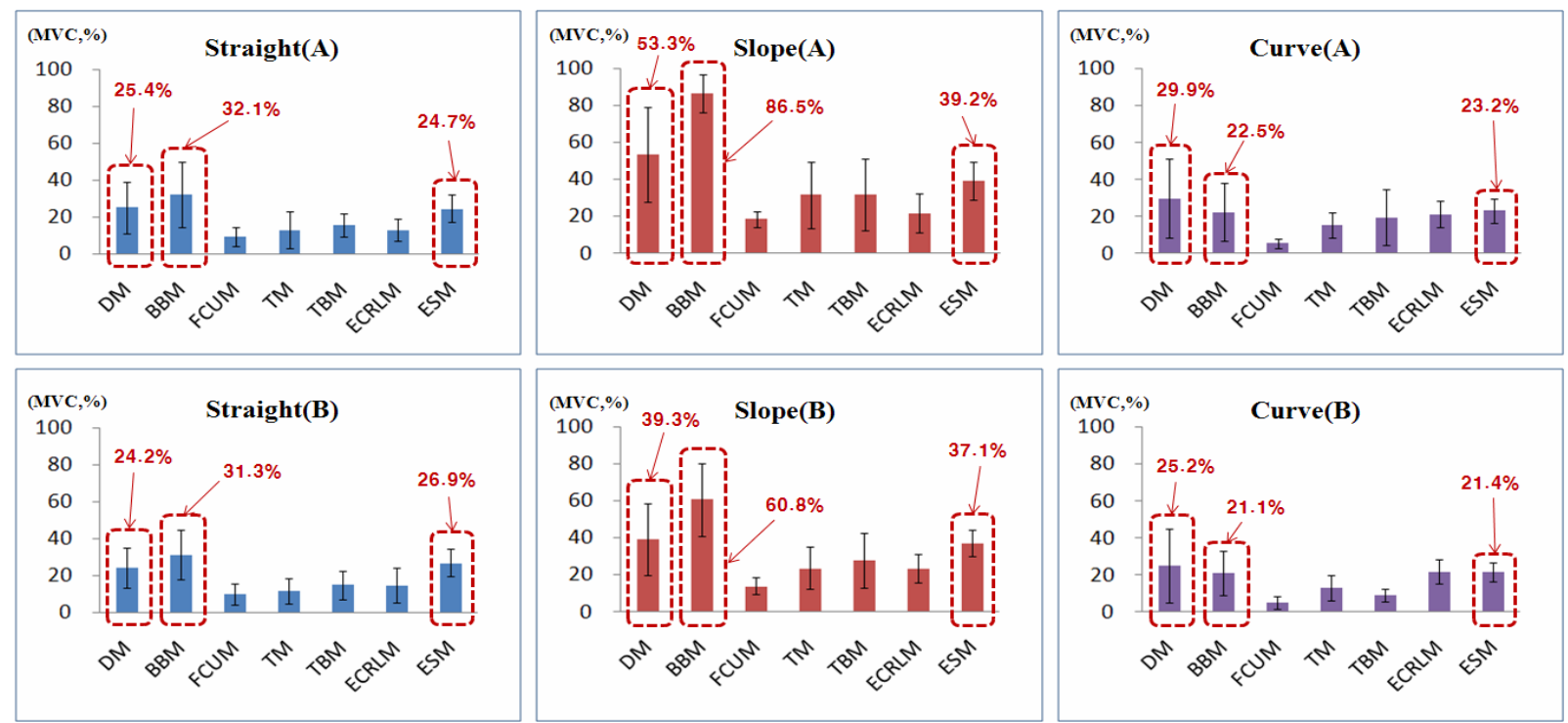

Figure 22. Comparison of muscle activities from drivability tests between shower carrier A and B in case of female subjects

$\mathrm{DM}:-49.2 \%, \mathrm{ESM}:-25.9 \%)$, 회전에서는 $-24.9 \%(\mathrm{ESM})$ 가 얻어졌다. 이를 분석하면, 경쟁제품 $(\mathrm{A})$ 에 비하여 시제 품 $(\mathrm{B})$ 에서 남성 피검자의 근활성도가 대폭 감소(최대 $-59.0 \%)$ 하여 근력 부담의 경감이 기대된다.

여성 피검자의 경우, 주행 조건 별 삼각근 $(\mathrm{DM})$, 위팔두갈 래근 $(\mathrm{BBM})$, 척주기립근 $(\mathrm{ESM})$ 이 현저하게 활성화되었다. 이러한 근육을 대상으로 경쟁제품(A) 대비 시제품(B)에 대 한 근활성도의 변화율을 비교한 결과, 평지직진에서는 8.9 $-4.7 \%$ (DM: $-4.7 \%, \mathrm{BBM}:-2.5 \%, \mathrm{ESM}: 8.9 \%$ ), 경사직 진에서는 $-5.4 \sim-29.7 \%$ (DM: $-26.5 \%, \mathrm{BBM}:-29.7 \%$, $\mathrm{ESM}:-5.4 \%$ ), 회전에서는 $-6.2 \sim-15.7 \%(\mathrm{DM}:-15.7 \%$, $\mathrm{BBM}:-6.2 \% \mathrm{ESM}:-7.8 \%)$ 가 얻어졌다. 이를 분석하면, 경쟁제품 $(\mathrm{A})$ 에 비하여 시제품 $(\mathrm{B})$ 에서 여성 피검자의 근활 성도가 감소(최대 $-29.7 \%$ )하여 근력 부담의 경감이 기대 된다.

이상의 결과를 종합하면, 샤워캐리어의 주행성 시험을 통 하여 측정된 피검자 근활성도의 상위 3 개소의 근육은 남녀 성별에 따라서 일부 상이한 결과가 얻어져, 향후 남녀의 체 격차이 등이 근활성도에 미치는 영향에 대한 연구가 필요 할 것으로 판단된다. 하지만, 각각의 성별에 있어서 경쟁제 품(A)과 시제품(B) 모두 활성화된 상위 3 개소 근육이 동 일하였고, 시제품 $(\mathrm{B})$ 에서 이들 근육의 근활성도가 현저하 게 감소되었다. 따라서, 본 연구에서 수행한 주행성 시험을 통하여 경쟁제품(A) 대비 시제품(B)의 우수한 주행 성능 이 확인되었고, 이는 주로 시제품의 경량화(Forelli: 85kg, Prototype: $65 \mathrm{~kg}$ )에 기인한 것으로 판단된다.

\section{Conclusions}

본 연구에서는 국내 장기요양기관에서의 요구사항을 반영 하여, 사용자의 편의성 향상과 수발자의 근력 부담 경감이 기대되는 샤워캐리어 시제품을 개발하였다.

Bed 부에 대해서는, 한국인 60대 고령자 신체치수를 반 영하여 Bed 부 크기 (길이: $1,900 \mathrm{~mm}$, 폭: $650 \mathrm{~mm}$ )를 도출 하였다. 또한 샤워 수발행위 시, 고령자에게 사용 편의성을 제공하고 수발자에게 근력 부담 경감이 기대되는 가변형 Headrest와 인체 머리형상을 반영한 Headform을 개발하였 다. 승하강 구동부에 대해서는, 저상형 침대로부터의 이송 및 샤워 수발행위 시 수발자의 근력 부담 경감을 위하여 최 저/최고 지상고를 600/1,100mm(Stroke: 500mm)로 설정 하였고, 이를 구현하기 위하여 Dual Actuator 내장의 3단 Column Lifting Module을 신규로 개발하였다. Base Frame 에 대해서는, 정역학적 전도해석을 통하여 전도 안전성이 확 보된 Wheelbase(길이: $1,250 \mathrm{~mm}$, 폭: $580 \mathrm{~mm}$ )를 도출하 였고, 구조 안전성이 확보된 일체형 Base Frame을 개발하 였다.

본 연구에서 개발한 샤워캐리어의 시제품에 대해서는, 경 쟁제품과 동일한 주행성 시험을 수행하였고, 20대 남성과 40대 여성 피검자의 근활성도를 비교/분석한 결과, 경쟁제품 대비 시제품의 주행성능이 우수한 것으로 확인되었다. 향후, 본 연구에서 얻어진 결과는, 샤워캐리어의 뿐만 아니라 다양 한 고령친화용품의 개발에도 유용하게 적용 가능할 것으로 기대된다. 


\section{Acknowledgements}

This study was performed with assistance from the research fund of the Ministry of Health and Welfare in Korea(A101945).

\section{References}

Electromyography, http://cafe.naver.com/ezfit.cafe (retrieved December 18, 2011).

iSTANDARD, http://www.istandard.or.kr (retrieved May 10, 2010).

Ministry of Health and Welfare, Extensive Analysis on the Data From the statistics Korea and the Basic Plan in Preparation of Low Birth rate and Elderly Society, 2006.

National Health Insurance, Long-term Care Insurance, http://www. longtermcare.or.kr(retrieved November 28, 2011).

Park, S. C. and Park, S. J., "A Study on Biomechanical Body Segment parameters of Korean Adults", Korean Association of Physical Anthropologists, 39, 1-31, 1996.

SEED technology, http://www.seedtech.co.kr (retrieved July 23, 2010).

The Korean Gerontological Society, Understanding of Gerontology, Daeyoung Munhwa Publishing Co., 142-143, 2002.

The Ministry of Health and Welfare, Survey of Living Conditions of the Elderly, 2008.
Cheol Woong Ko: cheko@kitech.re.kr

Highest degree: $\mathrm{Ph} . \mathrm{D}$, Department of Mechanical and Environmental Informatics, Tokyo Institute of Technology (TIT)

Position title: Senior Researcher, Gerontechnology R\&D Group, KITECH Areas of interest: Human Finite Element Modeling, Computer Simulation, Biomechanics, Biomedical Engineering

Keyoung Jin Chun: chun@kitech.re.kr

Highest degree: $\mathrm{Ph}$. D, Department of Biomechanics, Michigan State University

Position title: Senior Researcher, Gerontechnology R\&D Group, KITECH

Areas of interest: Development of senior-friendly product, Biomechanics

Kon Woo No: Timey2@nate.com

Highest degree: Bachelor, Department of Physical Therapy, Samyook University of Health Science and Social Welfare

Position title: Physical Therapist, Seoul National Seobu Senior Care Center of Rehabilitation Team

Areas of interest: Care \& Rehabilitation machinery

Date Received : 2011-12-06

Date Revised :2012-02-17

Date Accepted : 2012-02-20

\section{Author listings}

Deok Yeon Cho: dukyon@kitech.re.k

Highest degree: Master, Nano·IT Fusion Program, Seoul National

University of Science and Technology

Position title: Researcher, Gerontechnology R\&D Group, KITECH

Areas of interest: Mechanical Design 